

\title{
O BOM PROFESSOR SEGUNDO OS ALUNOS UNIVERSITÁRIOS DE FÍSICA
}

\begin{abstract}
Mauro Antonio Andreata - Bacharel em Física (UFRGS), mestre e doutor em Física (UFSCar), professor adjunto da Universidade Federal de Goiás/Catalão. mauroandreata@yahoo.com.br
\end{abstract}

Thaianne Lopes de Souza - Graduando em Física na Universidade Federal de Goiás/Catalão. thaiannefisica@gmail.com

RESUMO Neste trabalho, apresentamos a pesquisa que fizemos entre os alunos universitários de física, da UFPA/Santarém e da UFG/Catalão, com o objetivo de determinar as qualidades consideradas pelos mesmos como as mais eficientes para a docência. Utilizamos a técnica do questionário autoaplicado com duas questões abertas: "Por que desejo ser professor?" e "Que tipo de professor desejo ser?". Nosso estudo indica que, em geral, os alunos de física esperam boas aulas tradicionais ministradas por bons professores tradicionais.

Palavras-chave: Física. Paulo Freire. Professor.

ABSTRACT In this paper, we present the research we did among university students in physics, from UFPA/Santarém and UFG/Catalão, in order to determine the qualities considered by them as the most effective for teaching. We used the technique of self-applied questionnaire with two open questions: "Why do I want to be a teacher?" and "What kind of teacher I want to be?". Our study indicates that, in general, students of physics expect good traditional classes taught by good traditional teachers.

Keywords: Physics. Paulo Freire. Teacher.

\section{Introdução}

A preocupação com o professor e sua formação aumentou bastante nos últimos anos (BACCON; ARRUDA, 2010; SAVIANI, 2011; TANURI, 2000). Do século XX em diante todos começaram, ao menos no plano verbal, a reconhecer a importância do professor. 
Vejamos, para exemplificar, o depoimento do filósofo e educador italiano Giuseppe Lombardo-Radice (1879-1938), num livro cujo original foi publicado em 1912:

Podemos, portanto, repetir aqui aquela que é a mais rica de sentido entre todas as fórmulas didáticas: o método é o professor; a disciplina é o professor; é sua alma que domina e nela os alunos esquecem seu pequeno mundo, restrito e individual, e quase se esquecem de ser o que são ao sentir o que é, para todos, o professor (LOMBARDO-RADICE, 1950, p. 27, grifo do autor, tradução nossa).

Hoje sabemos que os professores não se improvisam e exigimos que recebam adequada formação, mas nem sempre foi assim. A história da educação nos ensina que ocorreram vários períodos em que o professor foi considerado irrelevante:

É verdade também que, em função da correlação econômica de forças, o trabalho docente tornou-se espaço para onde se canaliza tudo o que há de inadaptado, mal sucedido e fracassado em todos os campos da vida. A escola é um cais para onde a vida encaminha os navios avariados. Por isso, para a profissão de mestre faz-se uma seleção de um material humano fraco, imprestável e mutilado. É simbólico o fato de que houve época em que soldados reformados iam para o magistério. Os soldados reformados da vida ainda hoje preenchem 3/4 das fileiras docentes (VIGOTSKI, 2004, p. 451).

No Brasil, temos situação análoga:

Os professores, então [início da década de 1950], eram em grande maioria improvisados, pois assumiam a função docente profissionais liberais que passavam a dar aulas ou por inexistência de professores licenciados ou em muitos casos por fracasso na própria profissão. Assim, engenheiros, farmacêuticos, médicos, dentistas, agrônomos e até com certa frequência bacharéis em direito se tornavam professores de ciências. A falta de preparação do professor criava insegurança para atuação em aulas práticas e ceticismo sobre os resultados de tais métodos de ensino (KRASILCHIK, 1980, p. 165).

Uma pesquisa recente (PEREIRA et al., 2009), feita em dez cidades na região de Catalão/GO, constatou que, dos quarenta e dois professores ministrando aulas de física no Ensino Médio (em escolas estaduais) nenhum é graduado em física: $82 \%$ são graduados em matemática, $7 \%$ em pedagogia, $2 \%$ em biologia, 2\% em geografia e $7 \%$ não são graduados. 
Em 1685, preocupado com a situação do ensino, Jean Baptiste de La Salle (16511719), educador francês, abriu a primeira Escola Normal, ou seja, a primeira instituição para preparação dos professores elementares da história. A partir daí, os professores começaram a receber preparo especial para desempenhar adequadamente suas funções. No Brasil, a primeira Escola Normal foi instituída em Niterói-RJ, em 1835. “Tratava-se de uma escola bastante simples, regida por um diretor que era também o professor, com um currículo que praticamente se resumia ao conteúdo da própria escola elementar, sem prever sequer os rudimentos relativos à formação didático-pedagógica" (SAVIANI, 2008, pp. 14-15).

A moderna teoria educacional estabelece que, para ser bom professor, é preciso ser dotado de certo número de qualidades físicas, intelectuais e morais. Por exemplo, o educador brasileiro Paulo Reglus Neves Freire (1921-1997), em seu livro "Pedagogia da autonomia" (FREIRE, 2007), enumera vinte e sete saberes necessários à prática educativa: 1) rigorosidade metódica; 2) pesquisa; 3 ) respeito aos saberes do educando; 4) criticidade; 5) estética e ética; 6) corporeificação das palavras pelo exemplo; 7) risco, aceitação do novo e rejeição a qualquer forma de discriminação; 8) reflexão crítica sobre a prática; 9) o reconhecimento e a assunção da identidade cultural; 10) consciência do inacabamento; 11) o reconhecimento de ser condicionado; 12) respeito à autonomia do ser do educando; 13) bom senso; 14) humildade, tolerância e luta em defesa dos direitos dos educadores; 15) apreensão da realidade; 16) alegria e esperança; 17) a convicção de que a mudança é possível; 18) curiosidade; 19) segurança, competência profissional e generosidade; 20) comprometimento; 21) compreender que a educação é uma forma de intervenção no mundo; 22) liberdade e autoridade; 23) tomada consciente de decisões; 24) saber escutar; 25) reconhecer que a educação é ideológica; 26) disponibilidade para o diálogo; 27) querer bem aos educandos.

Os vinte e sete saberes supracitados sintetizam os princípios educacionais freirianos, sua maneira de pensar e fazer educação, visando produzir uma existência humana digna, justa e solidária.

Neste trabalho, contudo, queremos discutir as qualidades necessárias ao bom professor do ponto de vista dos alunos da licenciatura em física. Afinal, como diz o Paulo Freire, "saber que não posso passar despercebido pelos alunos, e que a maneira como me percebam me ajuda ou desajuda no cumprimento de minha tarefa de professor, aumenta em mim os cuidados com o meu desempenho" (FREIRE, 2007, p. 97).

\section{Metodologia}


Para descobrir os traços dominantes do bom professor, os pesquisadores recorreram a diversos meios de investigação. “[...] utilizou-se muito o método histórico. É possível, depois de ter anotado os nomes dos grandes pedagogos praticantes que a história nos apresenta como tais, analisar a sua personalidade" (PLANCHARD, 1982, p. 330, grifo do autor). Outra possibilidade: "Demasiadas vezes, também, parte-se de conceitos teóricos da educação e da instrução para formular, por via dedutiva, quais devem ser as capacidades do mestre" (idem, ibidem). Além disso, "muitos investigadores combinaram os resultados da observação direta e os dados obtidos por meio de inquéritos e questionários" (idem, p. 331). Naturalmente, cada meio de investigação tem suas vantagens e desvantagens.

Para evitar mal-entendidos, antes de discutir a pesquisa que fizemos, vamos recordar a conceituação de questionário:

\footnotetext{
Pode-se definir questionário como a técnica de investigação composta por um conjunto de questões que são submetidas a pessoas com o propósito de obter informações sobre conhecimentos, crenças, sentimentos, valores, interesses, expectativas, aspirações, temores, comportamento presente ou passado, etc. Os questionários, na maioria das vezes, são propostos por escrito aos respondentes. Costumam, nesse caso, ser designados como questionários autoaplicados. Quando, porém, as questões são formuladas oralmente pelo pesquisador, podem ser designados como questionários aplicados com entrevista ou formulários (GIL, 2009, p. 121).
}

As questões escolhidas para compor o questionário podem ser abertas, fechadas ou dependentes. "Nas questões abertas solicita-se aos respondentes para que ofereçam suas próprias respostas" (idem, p. 122, grifo do autor). Enquanto que "nas questões fechadas, pede-se aos respondentes para que escolham uma alternativa dentre as que são apresentadas numa lista" (idem, p. 123, grifo do autor). Finalmente, "há perguntas que só fazem sentido para alguns respondentes. [...] Neste caso, a pesquisa referente à opinião é dependente em relação à outra" (idem, ibidem, grifo do autor). Eis um apontamento em relação ao número de questões do questionário:

O número de questões depende da extensão dos objetivos e da complexidade do assunto. Mas é necessário considerar que de modo geral os respondentes não se sentem obrigados a responder ao questionário. Por essa razão convém que sejam incluídas apenas as questões rigorosamente necessárias para atender aos objetivos da pesquisa (idem, p. 127). 
Com setenta e cinco (75) alunos da licenciatura em física, da Universidade Federal do Pará/Santarém e da Universidade Federal de Goiás/Catalão, numa pesquisa em sala de aulas, usando a técnica do questionário autoaplicado, procedemos a um levantamento com o objetivo de estabelecer quais são as características desejáveis no professor de física. Nosso questionário autoaplicado continha duas questões abertas. Ei-las: "Por que desejo ser professor?" e "Que tipo de professor desejo ser?". Concedemos aos discentes trinta minutos para que pudessem responder, por escrito, aos dois questionamentos.

\section{Resultados}

Dos setenta e cinco (75) discentes consultados, seis (6) declararam que não desejam ser professor, nove (9) afirmaram que ainda estão em dúvida e dez (10) escolheram a licenciatura em Física por falta de opção (queriam fazer bacharelado em física ou outro curso não ofertado pela universidade). Ou seja, no nosso levantamento $33,3 \%$ dos alunos não querem ou ainda não decidiram se desejam ser professor. Cinquenta (50) discentes, isto é, $66,7 \%$ dos alunos almejam ser professor desde o início da licenciatura em física ou acabaram se interessando pela docência ao longo do curso.

Quanto às qualidades desejáveis no professor de física, os alunos mencionaram: 1) saber transmitir conhecimentos (20,0\%); 2) ser amigo dos alunos (14,7\%); 3) ter vocação para o ensino $(13,3 \%) ; 4)$ conhecer sua função $(10,7 \%) ; 5)$ ser atencioso $(9,3 \%)$; 6) ser dinâmico em suas aulas $(8,0 \%) ; 7)$ compartilhar experiências $(8,0 \%) ; 8)$ impor disciplina $(6,7 \%) ; 9)$ esclarecer as dúvidas dos alunos $(6,7 \%) ; 10)$ conhecer o aluno $(5,3 \%) ; 11)$ ajudar os alunos em suas dificuldades $(5,3 \%) ; 12)$ estimular os alunos $(5,3 \%) ; 13)$ aceitar opiniões diferentes $(4,0 \%) ; 14)$ ser humilde $(4,0 \%) ; 15)$ ter bom caráter $(4,0 \%) ; 16)$ interessar-se pelo ensino $(2,7 \%) ; 17)$ ser acessível $(2,7 \%) ; 18)$ facilitar a aprendizagem do aluno $(2,7 \%) ; 19)$ transmitir confiança $(2,7 \%) ; 20)$ ser inteligente $(1,3 \%) ; 21)$ ter bom humor $(1,3 \%) ; 22)$ falar com clareza $(1,3 \%) ; 23)$ ser psicólogo $(1,3 \%) ; 24)$ saber liderar $(1,3 \%)$.

Além das supracitadas qualidades desejáveis no professor, os alunos fizeram as seguintes observações gerais sobre ensino e docência: 1) o professor é muito importante; 2) o salário do professor é baixo; 3) ensinar não é uma tarefa fácil; 4) o ensino precisa melhorar.

A seguir reproduzimos, na íntegra, as afirmações que não se enquadram nas vinte e quatro qualidades desejáveis no professor e nem nas quatro observações gerais sobre ensino e docência apresentadas acima: 
1. Quatro afirmações que decorrem de experiências negativas dos alunos com seus professores:

a) "Desejo ser o professor que eu não tive, um professor que não mostre apenas as falhas dos alunos, não tenha somente a preocupação de passar conteúdo."

b) "Quero ensinar os alunos de outra forma, diferente da maneira que me ensinaram. Quero me empenhar bastante."

c) “Sei que pode ser batido, porém quero ser diferente no meu modo de ensinar."

d) "Quero ser professor para tentar mudar essa mesmice que vemos em nossas aulas.”

2. Duas afirmações que decorrem de experiências positivas na prática docente:

a) "Gostei da experiência de repassar o conhecimento adquirido. Quero ser professor para ajudar as pessoas que querem aprender."

b) "Sinto prazer ao falar, ao me expressar e ensinar uma turma, ainda mais quando a vejo aprendendo."

3. Três afirmações que indicam experiências pessoais mais amplas:

a) “Ser docente de física é meu plano B. O que mais me atrai é o desafio de humanizar as ciências exatas. Além de almejar uma maior atratividade para o curso, focando a aplicabilidade da física no cotidiano."

b) “Ser professor vai além do ensino do conteúdo programático, transpassa os muros da escola, tem que ter paixão e sentir prazer. Educar é formar valores nos discentes."

c) "Um professor, antes de ensinar física ou outra disciplina, deve ser um exemplo para seus alunos, comportando-se bem e se expressando de maneira adequada, preparando o aluno para que seja um bom cidadão."

4. Uma afirmação que indica sofrimento físico e psicológico:

a) "Quando entro numa sala de aulas, começo a tremer e a suar frio, minha voz fica presa e realmente não sei o que quero fazendo essa licenciatura."

\section{Discussão}


Gostaríamos de comparar nosso estudo com recentes pesquisas similares feitas em solo brasileiro, mas fomos incapazes de localizá-las. Resta-nos fazer comparação com o referencial teórico, ou seja, com os princípios educacionais freirianos. Notamos que as vinte e quatro qualidades desejáveis no professor, mencionadas pelos educandos em nossa pesquisa, incluem algumas que vão ao encontro dos desejos formulados pelos educadores, filósofos e psicólogos da educação. Apresentamos a seguir alguns exemplos.

14,7\% dos alunos, consultados em nossa pesquisa, querem um professor amigo dos alunos. $13,3 \%$ esperam que o professor tenha vocação para o ensino. 10,7\% pedem que conheça sua função. 4,0\% dizem que o professor deve aceitar opiniões diferentes. 4,0\% recomendam humildade ao professor. Eis o que pensa Paulo Freire sobre tais questões:

\footnotetext{
O meu respeito de professor à pessoa do educando, à sua curiosidade, à sua timidez, que não devo agravar com procedimentos inibidores exige de mim o cultivo da humildade e da tolerância. Como posso respeitar a curiosidade do educando se, carente de humildade e da real compreensão do papel da ignorância na busca do saber, temo revelar o meu desconhecimento? Como ser educador, sobretudo numa perspectiva progressista, sem aprender, com maior ou menor esforço, a conviver com os diferentes? Como ser educador, se não desenvolvo em mim a indispensável amorosidade aos educandos com quem me comprometo e ao próprio processo formador de que sou parte? Não posso desgostar do que faço sob pena de não fazêlo bem (FREIRE, 2007, p. 67).
}

6,7\% dos alunos acreditam que o professor deve impor disciplina. Paulo Freire comenta o assunto:

O que sempre deliberadamente recusei, em nome do próprio respeito à liberdade, foi sua distorção em licenciosidade. O que sempre procurei foi viver em plenitude a relação tensa, contraditória e não mecânica, entre autoridade e liberdade, no sentido de assegurar o respeito entre ambas, cuja ruptura provoca a hipertrofia de uma ou de outra (FREIRE, 2007, p. 108).

$5,3 \%$ dos alunos julgam que o bom professor estimula seus alunos. Paulo Freire observa:

Uma das tarefas essenciais da escola, como centro de produção sistemática de conhecimento, é trabalhar criticamente a inteligibilidade das coisas e dos fatos e a sua comunicabilidade. É imprescindível portanto que a escola instigue 
constantemente a curiosidade do educando em vez de "amaciá-la" ou "domesticá-la" (FREIRE, 2007, pp. 123-124).

$1,3 \%$ dos alunos pedem ao professor que tenha bom humor. Encontramos essa exigência no trabalho de vários autores. Eis o que declara, ao discutir a alegria e o bom humor, Paulo Freire:

O meu envolvimento com a prática educativa, sabidamente política, moral, gnosiológica, jamais deixou de ser feito com alegria, o que não significa dizer que tenha invariavelmente podido criá-la nos educandos. Mas, preocupado com ela, enquanto clima ou atmosfera do espaço pedagógico, nunca deixei de estar (FREIRE, 2007, p. 72).

Ao comparar os vinte e sete saberes freirianos com as vinte e quatro qualidades mencionadas pelos alunos da nossa pesquisa, notamos que Paulo Freire e os discentes concordam em aproximadamente $50 \%$ dos casos.

Um ponto de discordância: a principal qualidade do professor, segundo os alunos, é saber transmitir conhecimentos. Eis a afirmação de um discente: "Transmitir conhecimentos é, para mim, um gesto de grande nobreza”. O Paulo Freire, contudo, critica o que ele chama de concepção "bancária" da educação, pois nessa concepção "a educação é o ato de depositar, de transferir, de transmitir valores e conhecimentos" (FREIRE, 2010, p. 67). O que ele defende é uma concepção problematizadora e libertadora da educação.

\section{Conclusão}

Nossa pesquisa, junto aos alunos universitários de física, indica que a maioria dos discentes ainda pensa que o professor é um mero transmissor de conhecimentos. O professor é visto como aquele que sabe, o detentor do conhecimento. Citemos um dos alunos consultados em nosso levantamento: “Um professor é um tipo de 'porteiro do conhecimento', que abrirá as portas para que o aluno possa conhecer mais o mundo.” Por isso, nenhum deles criticou o verbalismo e o dogmatismo do professor, o uso quase exclusivo das tradicionais aulas expositivas. Não sugeriram métodos ativos de ensino, não suspeitam que seja possível colocar o aluno no centro do processo de ensino-aprendizagem. Os alunos atribuem demasiada importância ao conteúdo. Por essa razão, deixaram claro que se preocupam bastante em descobrir maneiras de transmitir melhor o conteúdo. Não mencionaram a cooperação entre os professores e entre os alunos, o autogoverno do aluno e a liberdade no trabalho escolar. 
Em resumo, nosso levantamento indica que, em geral, o aluno universitário de física espera boas aulas tradicionais ministradas por bons professores tradicionais. Essa conclusão não causa surpresa, pois os alunos costumam ter somente aulas tradicionais desde o Ensino Fundamental, ou seja, conhecem apenas o método expositivo. Paulo Freire já dizia que, em todos os níveis do ensino brasileiro, "há uma quase enfermidade da narração. A tônica da educação é preponderantemente esta - narrar, sempre narrar" (FREIRE, 2010, p. 65).

\section{Agradecimentos}

Os autores agradecem à CAPES, pois o presente trabalho foi realizado com apoio do Programa Institucional de Bolsa de Iniciação à Docência - PIBID, da CAPES - Coordenação de Aperfeiçoamento de Pessoal de Nível Superior - Brasil.

\section{Referências}

BACCON, Ana Lúcia Pereira; ARRUDA, Sergio de Mello. Os saberes docentes na formação inicial do professor de física: elaborando sentidos para o estágio supervisionado. Ciência e Educação, v. 16, n. 3, pp. 507-524, 2010.

FREIRE, Paulo. Pedagogia da autonomia: saberes necessários à prática educativa. 35. ed. São Paulo: Paz e Terra, 2007. 146 p.

FREIRE, Paulo. Pedagogia do oprimido. 49. reimp. São Paulo: Paz e Terra, 2010. $213 \mathrm{p}$.

GIL, Antonio Carlos. Métodos e técnicas de pesquisa social. 6. ed. São Paulo: Atlas, 2009. $200 \mathrm{p}$.

KRASILCHIK, Myriam. Inovação no ensino das ciências. In: GARCIA, Walter E. (coord.). Inovação educacional no Brasil: problemas e perspectivas. São Paulo: Cortez / Autores Associados, 1980. 264 p.

LOMBARDO-RADICE, Giuseppe. Leccíones de didáctica y recuerdos de experiencia docente. Barcelona: Labor, 1950. 483 p. 
PEREIRA, Ana Rita et al. Perfil dos professores de física no Ensino Médio na região de Catalão - Goiás. In: SIMPÓSIO NACIONAL DE ENSINO DE FÍSICA “Formação Continuada de Professores em Serviço: Educação de Qualidade para uma Sociedade da Aprendizagem", 18., 2009, Vitória. Disponível em: <http://www.sbf1.sbfisica.org. br/eventos/snef/xviii/sys/resumos/T0096-1.pdf>

PLANCHARD, Émile. A pedagogia contemporânea. 8. ed. atual. Coimbra: Coimbra Editora, 1982. 700 p.

SAVIANI, Dermeval. A pedagogia no Brasil: história e teoria. Campinas: Autores Associados, 2008. 259 p.

SAVIANI, Dermeval. Formação de professores no Brasil: dilemas e perspectivas. Poíesis Pedagógica, v. 9, n. 1, pp. 07-19, jan/jun. 2011.

TANURI, Leonor Maria. História da formação de professores. Revista Brasileira de Educação, n. 14, pp. 61-88, mai/jun/jul/ago. 2000.

VIGOTSKI, Lev Semenovich. Psicologia pedagógica. Tradução do russo de Paulo Bezerra. 2. ed. São Paulo: Martins Fontes, 2004. 561 p. 